\title{
Measuring Conversational Journalism: An Experimental Test of Wiki, Twittered and "Collaborative" News Models
}

\author{
Doreen Marie Marchionni ${ }^{1}$ \\ ${ }^{1}$ Communication \& Theatre, Pacific Lutheran University, Tacoma, Washington, USA \\ Correspondence: Doreen Marchionni, 133 Ingram Hall, Pacific Lutheran University, Tacoma, WA 98447, USA. \\ Tel: 1-253-538-6307. E-mail: marchidm@plu.edu
}

Received: September 2, $2013 \quad$ Accepted: October 19, $2013 \quad$ Available online: October 28, 2013
$\begin{aligned} & \text { doi:10.11114/smc.v1i2.260 } \\ & \text { URL: http://dx.doi.org/10.11114/smc.v1i2.260 }\end{aligned}$

\begin{abstract}
Journalism-as-a-conversation has become a catchphrase for audience participation in the news. Largely missing from the literature, though, are clear conceptual and operational definitions of conversation that allow theory building for purposes of explanation and prediction. This exploratory study sought to help close that gap by theoretically indentifying a way to measure conversation's features in terms of the audience experience, then testing the model on outcome measures of perceived credibility and expertise in three online contexts: twittered, wiki and "collaborative" news. Conversation's proposed features: coorientation/homophily (perceived similarity), social presence, friendliness, informality and interactivity. Findings suggest the features of perceived similarity to a journalist and online interactivity are key. Somewhat problematic is the conversational feature of informality with an audience. Results suggest journalists can easily come across as too casual with readers to the detriment of trust.
\end{abstract}

Keywords: conversational journalism, participatory journalism, experiment, psychological processing, citizen journalism

\section{Introduction}

\subsection{The Problem}

Today's news landscape is seeing an explosion in Web tools for conversational journalism, or what some refer to as citizen-journalist collaboration (Briggs, 2010; Gillmor, 2006; Rosen, 2006), including the microblog Twitter. Using Twitter, Brian Stelter of The New York Times and Andrew Carvin of National Public Radio in the U.S. represent a new generation of journalists who tap their audiences for help on stories, the latter in heart-pounding rapidity during the 2011 Arab Spring uprisings (Hermida, Lewis \& Zamith, 2012). Although not the norm, such collaborations stand in contrast to decades of traditional journalism as a lecture, in which the journalist alone presumably knows what is news and conducts a monologue with the public on such matters, or perhaps a dialogue with public officials and other elites. Citizens here are at best passive bystanders. The reform effort known as "public/civic journalism" started to advance conversation in the 1990s, though, and now Web tools such as Twitter and Wikinews are pushing its boundaries further.

Despite conversation's growing popularity, though, little empirical research followed to help people understand what precisely it is in terms of measureable features and how best to apply it to journalism's most treasured values, credibility and expertise. Audience-centered literature on public/civic journalism, "interactive journalism" and "participatory journalism" is replete with references to conversation but often as little more than a buzzword. As a result, the literature is wanting on clear operational definitions that allow theory building for purposes of explanation and prediction, a key goal in science. From a practical standpoint, such theoretical clarity could also help journalists determine how best to tap audiences to tell more complete, human stories.

\subsection{This Study's Response to the Problem}

This exploratory study attempts to correct the above problem and is part of a larger research program designed to explicate journalism-as-a-conversation. That program includes two prior studies by the author. The first identified a half dozen variables that appear to theoretically index the concept in the audience experience: coorientation/homophily (perceived similarity), social presence, friendliness, informality and interactivity (Marchionni, 2013). The second study tested that theoretical model in a controlled experiment by comparing traditional, Associated-Press style stories with what Thorson and Duffy (2006) describe as "collaborative" news, 
some accompanied by 1-minute personal videos of journalists designed to convey their humanness (Marchionni, 2013).

The present online newspaper experiment builds on these two studies. Rather than comparing traditional stories with collaborative/conversational ones as in Experiment 1, this study compares three types of conversational stories using the same six-variable measurement model, none with videos this time: news derived with the help of Twitter, Wikinews written by and for private citizens and the same "collaborative" news from Thorson and Duffy's (2006) Media Choice Model. Based on results from the previous studies, the overarching hypothesis here is that participants will perceive the proposed conversational features and outcome variables of credibility and expertise differently across the three types of news stories, in part based on native differences in those Web tools. The specific hypotheses will be discussed shortly.

\subsection{Relevant Scholarship on Conversational Journalism}

Journalism-as-a-conversation, a phrase Carey (1992) is credited with coining (Kunelius, 2001) and a rallying cry for public journalism reforms, occupies odd standing in the literature. On the one hand, casual references to it abound in audience-centered literatures, not to mention news sites that invite audiences to 'join the conversation!' On the other hand, conversation suffers from a paucity of deep, clear theorizing. This may be because scholars lack a common language for the concept's central features/variables, even where certain descriptions point to identifiable terms in the broad context of communication research. The first step in theorizing conversation, then, is using those terms. A detailed discussion of the proposed model can be found in the author's conceptual study, mentioned earlier.

To summarize that study, Carey (1992) and Anderson, Dardenne and Killenberg (1996) make clear by inference that a core dimension of conversation is socio-psychological, or interpersonal. More specifically, citizens must perceive journalists as human and social, or what scientists might refer to as social presence; as non-lecturing and casual in tone, or what might be called informality; as friendly to the extent of being open to citizen contribution to news processes, or friendliness; and as similar to the audiences they serve in a democracy both intellectually and demographically, or respectively coorientation and homophily.

Because Carey's (1992) and Anderson et al.'s (1996) works largely pre-date the rise of the commercial Internet, their conceptualization of conversation lacks the technological mechanism of conversation in the $21^{\text {st }}$ century. For that, studies on "interactive journalism" (Chung, 2008; Rosenberry, 2005; Schultz, 2000) and "participatory journalism" (Domingo et al., 2008; Singer et al., 2011) fill a crucial gap and suggest that interactivity, or journalists' strategic use of Web tools to engage audiences, also is a key dimension of conversation. Key citations that further informed each concept/variable in the measurement model are as follows:

* Social presence - Perceived humanness of journalist (Gunawardena, 1995; Swan, 2002)

* Coorientation - Perceived intellectual similarity to a journalist (Wackman, 1973)

* Homophily — Perceived demographic similarity to a journalist (McCroskey, Richmond \& Daly, 1975)

* Friendliness - Perceived openness and accessibility of journalist to citizen collaboration (Norton \& Pettigrew, 1977)

* Informality — Perceived relaxed, casual tone with audience (Althen, 1992)

* Interactivity - Perceived use of the Web by journalist to interact with citizens (Rafaeli, 1988)

To continue building theory on conversation, the present exploratory study tests those variables in an experiment that compares three types of conversational texts on outcome measures of credibility and expertise. The theoretical groundwork for the latter rests in related research, namely that people seek a human presence in the news and judge credibility accordingly (Newhagen \& Nass, 1988), treat various electronic media as though they were human (Reeves \& Nass, 1996) and respond positively in terms of credibility to the use of everyday citizens in news stories (Meyer, Marchionni \& Thorson, 2010).

\subsection{Hypotheses and Research Design}

As with Experiment 1, the present study is a controlled experiment because it is the best method for testing causal relationships between variables, in this case between the conversational variables and between those variables and outcome measures of perceived credibility and expertise in different story contexts. Together the experiments are designed to shed light on journalism-as-a-conversation, defined here as a multifaceted collaboration between professional journalists and citizens, by testing how well the author's proposed measurement model works in actual empirical tests. What follows is a description of the present study's independent variable, article type, and hypotheses related to the dependent variables, or the six conversation variables, credibility and expertise. 
The first article type is called collaborative. It comes from Thorson and Duffy's (2006) Media Choice Model, which extends uses and gratifications theory to the online environment. The model identifies several types of news stories from which readers can choose these days. In their model, these different types are referred to as "voice." Traditional news, such as what a reader might encounter in a just-the-facts wire-service story, is but one option. Another type is collaborative news, such as when journalists report they are working closely with their audience as sources to cover a story, perhaps in a detailed editor's note. Here, newspaper stories are reported from the vantage point of the audience, emphasizing citizen quotations and perspectives and containing what might be called "human-interest," or soft, ledes (story introductions). This experiment compares stories in terms of that news type.

The second article type is one derived from Twitter. Launched in October, 2006, the social network Twitter came into its own as a site where people could quickly update each other on where they were, what was going on and other matters in short posts distributed by instant messages, mobile phones, e-mail or the Web (Hermida, 2010; Java, Song, Finin \& Tseng, 2007). The maximum number of characters allowed for any "tweet" is 140 , hence its popularity as a kind of headline service. Some journalists now embrace Twitter as a crowd-sourcing tool for quickly accessing citizen sources on various topics in real time and in a publicly viewable timeline. Once completed, that sourcing can then be telegraphed within the body of an actual news story on a newspaper site, such as a line that reads, "Several people in this story were contacted with the help of the micro-blogging tool, Twitter." The present study defines Twitter in terms of that crowd-sourcing ability.

The third and final article type is Wikinews. Like Wikipedia, Wikinews features content written and edited by private citizens, though its self-described "synthesis articles" often point to reference material from mainstream journalists for additional information and background. In its masthead, Wikinews proudly proclaims, "The free news source you can write!" to highlight private citizens, not professional journalists, are at the heart of the news operation. This type of news represents a tangential collaboration between professionals and citizens, but it is worth exploring in this study because of the growing popularity of citizen news sites. Wikinews stories tend to be written in a somewhat informal style, straying at times toward encyclopedic entries because they lack summary paragraphs, or "nutgrafs," essential to discerning the main point of a news story.

Wiki stories also do not include bylines of the citizens who wrote them or any other identifying features of the citizen reporter. This is in keeping with the site's goal to present news in a neutral manner, as described in its mission statement on its site. The present study defines Wikinews as a news site largely created by and for private citizens.

In light of the previous discussion, the first set of hypotheses address potential differences for conversation variables in each of the three story conditions. Those variables represent specific features of conversation, and the study predicts those features will vary across story conditions based on the unique attributes of the condition or Web tool.

To summarize those differences, the Twitter condition consists of two parts. It shows a screenshot of a journalist on Twitter soliciting the insights and experiences of citizen followers to tell a more complete, authentic story, then shows the results of that exchange in an actual newspaper story that briefly mentions the journalist used Twitter for crowdsourcing. That short, casual exchange on Twitter is designed to elicit high scores for several conversational features in the otherwise traditional-looking story that followed on the newspaper's site: social presence, by revealing the human behind the news; informality, by showing a casual exchange between journalist and citizen source in reporting a story; and friendliness, by showing the journalist demonstrating an open attitude toward strangers who might be able to offer information for a story. Indeed, while this study expects moderate scores on the other conversational features, scores on these three in the Twitter condition are expected to be higher than in any other condition, hence:

H1: Scores on the conversation variables social presence, informality and friendliness will be higher in the Twitter condition than in any other condition.

The Wikinews condition differs in several key ways from other conditions. Most obviously, everyday citizens just like the reader wrote the story, suggesting perceived similarity measures of coorientation and homophily would be higher here than anywhere else. But nothing in the story gives a human dimension to its citizen writers, or social presence. Nor does the story explicitly say they interacted with everyday people to research the story, interactivity, or reveal the writers as having an open manner toward those citizens, friendliness. As a result, the study predicts scores for these three variables likely will be lower in this condition than any other, hence the following predictions:

H2a: Scores on the conversation variables coorientation and homophily will be higher in the Wikinews condition than in any other condition. 
H2b: Scores on the conversation variables social presence, interactivity and friendliness will be lower in the Wikinews condition than in any other condition.

The final story condition, collaborative, offers something of a balance between the other two story types on conversational variables. It involves no social networking or group writing/editing of news (wiki) but rather a call-out to readers on a mainstream news site soliciting citizen help. As a result, this study expects scores for all conversation variables here to be strong, though not exceedingly high, and never low. The one exception might be interactivity. Rather than showing interaction with readers, as the Twitter condition does, the collaborative stories explicitly tell readers this in a detailed editor's note above the story's byline. That note stresses the journalist has been in contact with her audience via e-mail and phone to help tell a more complete story and that a public forum is scheduled in the newspaper's community room for further discussion and possible follow-up stories. This note in particular is designed to drive home the interactivity question with study participants, yielding the highest interactivity scores of all conditions. For other conversation variables, this study expects collaborative stories never to have the lowest means among conditions:

H3a: Scores on the conversation variable interactivity will be higher in the collaborative condition than in any other condition.

H3b: Scores on the conversation variables informality, friendliness, coorientation, homophily and social presence in collaborative stories will never be the lowest of conditions.

The final hypothesis relates to how expert and credible participants view the different stories. Definitions of media-related credibility abound. Generally, credibility is defined as a multidimensional construct that measures the perceived believability of a message (article), source (journalist or news site) or medium.

This study defines credibility as material produced that the audience views as both factual and accurate. This experiment focuses on credibility at the level of the message, or article, and at the level of source (news site). In light of Newhagen and Nass' (1988) findings that newspaper credibility is most accounted for by the institution, which people view as cold, and research that shows people seek a human presence in news, this study predicts credibility is not just a rational but a social concept. These social aspects are subtle, if not fragile, though. Meyer, Marchionni and Thorson (2010), for instance, found social presence sometimes worked against perceived credibility in various news stories, or at least did not help. Perceived coorientation, on the other hand, often helped with trust, particularly in Thorson and Duffy's (2006) collaborative conditions.

Closely related to credibility is the concept of expertise. Hovland et al. (1953) suggest credibility has two dimensions, "trustworthiness" and "expertise," and that indicators of expertise include perceived similarity to the message recipient in status, values, interests and needs, or social background. More recently, Perloff (2003) argues expertise, or special skills or know-how, is a core characteristic of credible communicators. The present study embraces that definition. But he notes whether a communicator should emphasize expertise or similarity to another can be tricky. When an issue concerns factual matters, for instance, an expert's intellectual knowledge might be more persuasive than similarity (Perloff, 2003).

In light of the previous hypotheses, this study expects that although the Wikinews stories would be highest on coorientation and homophily, they might do poorly on interactivity and friendliness and, therefore, may not be strong on credibility and expertise. In the same vein, though the Twitter condition is expected to score well on friendliness, its high score for social presence might hurt, or at least not help, perceived credibility and expertise. That leaves the collaborative condition, where interactivity scores likely would be the highest and where scores on other conversation variables would be moderate in comparison to other conditions and never the weakest. Thus, the following hypothesis:

H4: Scores on perceived article credibility, source credibility and expertise will be highest in the collaborative condition.

\section{Method}

This study is a controlled experiment, designed to test relationships between variables in the author's proposed theoretical measurement model of conversation. Details on sampling, stimulus materials and design follow.

\subsection{Participant Characteristics}

The study drew on a convenience sample of students $(\mathrm{N}=67)$ typical of experiments from two large-lecture mass media courses at a Mid-West university in the United States. More females (77.6 percent) than males (22.4 percent) took part in the study. Other sample demographics: white (77.6 percent), Asian (17.9 percent) and African-American ( 3 percent); graduate students (34.3 percent), freshman (28.4 percent), juniors (23.9 percent) and sophomores (10.4 percent); native U.S. citizens (82.1 percent) and non-natives (17.9 percent). 


\subsection{Sampling Procedures}

Students volunteered to participate in the study for class credit, meeting the random-selection requirement of a controlled experiment. The author asked them to sign consent forms, though the school's Institutional Review Board did not require consent because of the study's "exempt-from-review" status. Participants received a card that randomly assigned them to one of three versions of the study with various combinations of articles in different orders by topic. This met the experiment's requirement for random assignment to conditions.

\subsubsection{Sample Size, Power, and Precision}

To determine an appropriate sample size before the experiment began, the study relied on gPower analysis, a software program designed to help determine sample sizes for different methods, as well as the researcher's previous experimental research, including Experiment 1. Recommended sample size was 52-74 participants, depending on desired effect magnitude. Given the exploratory nature of the study, theory did not dictate a specific effect size.

\subsubsection{Measures and Co-Variates}

For the independent variable article type/story condition (IV), the study used stories of potential interest to its college participants: job prospects upon graduation, college plagiarism tools to catch cheaters and college drinking. For each topic, this study had a Twitter, Wikinews and collaborative version, for a total of nine stories. Stories were roughly equal in length, or about 300 words. In the case of Twitter, the exchange between journalist and fellow Twitter users did not exceed 100 words to minimize participant fatigue after reading both the exchange and short news story that arose from it. The study took most participants about 30 minutes to complete.

This study balanced topics and conditions to minimize potential design-order effects. This produced three versions of the online study with various combinations of those stories in different orders. As such, participants had equal opportunity to read each type of article by topic.

\section{Independent Variables}

* Collaborative: Thorson and Duffy's (2006) collaborative news story appeared more similar to a traditional news story than stories in other conditions, with a masthead from an actual community newspaper. The stimulus materials included more citizen quotes than traditional stories, though. The stories also contained human-interest ledes and information both in the body of the story and in a colorful editor's note above the story byline that indicated the reporter was talking to many citizens in the community to gather information for the story. Each story ended with an email tagline to contact the journalist.

* Twitter: This study used the Twitter masthead and other design features and typography to aid external validity. The tweet featured a brief exchange between a fictional journalist seeking information for a story she was pursuing and everyday citizens who might know something about the issue. After participants read the exchange, they then read a short news story from a community newspaper Web site that included brief references to the journalist having used Twitter to help report the story. That story was roughly the same length as those in other conditions.

* Wikinews: This study used the Wikinews masthead and other typographical features, again to help provide external validity, as well as no bylines, an informal, almost encyclopedic writing style and "source" lines with references to mainstream news stories. But the stories in this study differed in one way from real Wikinews texts. In order to highlight that the conversation is between citizens, begin/end tags were used in the text to draw attention to the beginning and end of material that each of two citizens contributed to the story.

\section{Dependent Variables}

All survey questions about each story in the freeonline.com instrument were Likert-style dependent variables (DVs) with five options, from strongly disagree (1) to strongly agree (5). Some items had negative wording to minimize potential pattern-response bias; they were re-coded prior to statistical analysis. The six conversation variables acted as a manipulation check on the IV. In other words, they revealed whether participants viewed Twitter, Wikinews and collaborative story conditions as conversational. The three outcome variables, meanwhile, tested how trustworthy and expert readers found the stories. Finally, this study used "topic interest" as a control variable in the event readers found certain story topics more interesting than others. (See Appendix 1 for all survey questions.)

\subsubsection{Research Design}

This was a single-factor, within-subjects controlled experiment, the lone independent variable (IV) being story type at three levels and the dependent variables (DVs) being the six conversational features and the outcome measures of article credibility, source credibility and expertise. 


\subsubsection{Manipulation Checks}

This study relied on two manipulation-check questions. The first asked participants at study's end what they thought the experiment was about, to ferret out those who may have answered questions based on what they thought the researcher wanted. No answer suggested eliminating that person's data. The second question tried to discern if participants generally recognized differences between the three experimental conditions. They did, correctly answering questions about the Twitter condition 95 percent of the time, 91 percent of the time in collaborative and 79 percent of the time in Wikinews.

\section{Results}

Overall, data from the study offered modest support for the proposed measurement model of journalism-as-a-conversation, the main purpose of the study. Participants also somewhat consistently rated Thorson and Duffy's (2006) collaborative news approach as more credible and expert than the other story types. The following sub-sections lay out the details.

\subsection{Recruitment}

The author recruited students from a master's course in strategic communications and an undergraduate course on principles of American journalism during spring semester 2009. They signed a form indicating their desire to participate that included instructions on where to take the study on campus. Three participants' data largely were missing, apparently because they forgot to save their answers at the end of the survey. That left complete answers for 67 participants.

\subsection{Statistics and Data Analysis}

Preliminary analyses using SPSS software began with principal-components extraction on each of the study's 10 variables, using varimax rotation to aid interpretability. This was a check on how well items measured their latent constructs, or construct validity. Many items for coorientation and homophily loaded together across conditions while others loaded weakly and/or on separate factors. So primary analyses used a new, single variable from items with the strongest factor loadings. Each variable also reliably measured its construct, with most Cronbach's alphas in the range of .85-.99, well above the acceptable cutoff of .70 that Tabachnick and Fidell (2007) recommend. Topic interest was marginally significant, as was story/order, so both were statistically controlled.

To test hypotheses, the author ran a series of multivariate analyses of covariance (MANCOVAs) with Bonferroni post-hoc comparisons (Tables 1A and 1B). An initial check of power results showed most significant findings in omnibus F-tests were well within the recommended range of .70-1.0 (Tabachnick \& Fidell, 2007), meaning the study's sample size was adequate (Table 1A).

Table 1A. Multivariate analyses of co-variance (omnibus F-tests): Impact of story type on dependent variables for all topics, after controlling for topic interest and study/order.

\begin{tabular}{|c|c|c|c|c|c|c|c|}
\hline \multirow[b]{2}{*}{ Variables } & \multicolumn{3}{|c|}{ Story Type } & \multirow[b]{2}{*}{ F } & \multirow[b]{2}{*}{ df } & \multirow[b]{2}{*}{$\eta^{2}$} & \multirow[b]{2}{*}{ Power } \\
\hline & $\begin{array}{l}\text { Twitter } \\
\text { mean } \\
(\mathrm{SD})\end{array}$ & $\begin{array}{l}\text { Wikinews mean } \\
\text { (SD) }\end{array}$ & $\begin{array}{l}\text { Collaborative } \\
\text { mean } \\
\text { (SD) }\end{array}$ & & & & \\
\hline Coorient/ & 3.21 & 3.26 & 3.30 & .22 & 2,196 & .00 & .08 \\
\hline Homophily & $(.59)$ & $(.51)$ & (.44) & & & & \\
\hline Social & 2.56 & 2.32 & 2.48 & 2.19 & 2,196 & .02 & .44 \\
\hline Presence & $(.80)$ & $(.65)$ & $(.84$ & & & & \\
\hline Interactivity & $\begin{array}{l}3.66 \\
(.82)\end{array}$ & $\begin{array}{l}2.58 \\
(.96)\end{array}$ & $\begin{array}{l}4.00 \\
(.63)\end{array}$ & $56.42^{* *}$ & 2,196 & .37 & 1.00 \\
\hline Informality & $\begin{array}{l}3.02 \\
(.90)\end{array}$ & $\begin{array}{l}3.56 \\
(.84)\end{array}$ & $\begin{array}{l}3.40 \\
(.82)\end{array}$ & $6.43 * *$ & 2,196 & .06 & .90 \\
\hline Friendliness & $\begin{array}{l}3.60 \\
(.57)\end{array}$ & $\begin{array}{l}3.41 \\
(.48)\end{array}$ & $\begin{array}{l}3.74 \\
(.52)\end{array}$ & $6.85^{* *}$ & 2,196 & .07 & .92 \\
\hline Expertise & $\begin{array}{l}2.98 \\
(.87)\end{array}$ & $\begin{array}{l}2.83 \\
(.74)\end{array}$ & $\begin{array}{l}3.19 \\
(.79)\end{array}$ & $3.46^{*}$ & 2,196 & .03 & .64 \\
\hline $\begin{array}{l}\text { Article } \\
\text { Credibility }\end{array}$ & $\begin{array}{l}3.34 \\
(.65)\end{array}$ & $\begin{array}{l}2.94 \\
(.82)\end{array}$ & $\begin{array}{l}3.60 \\
(.66)\end{array}$ & $14.59^{* *}$ & 2,196 & .13 & 1.00 \\
\hline $\begin{array}{l}\text { Web Site } \\
\text { Credibility }\end{array}$ & $\begin{array}{l}3.15 \\
(.63) \\
\end{array}$ & $\begin{array}{l}2.64 \\
(.71) \\
\end{array}$ & $\begin{array}{l}3.46 \\
(.60) \\
\end{array}$ & $27.28^{* *}$ & 2,196 & .22 & 1.00 \\
\hline
\end{tabular}


$* \mathrm{p}<.05 \quad * * \mathrm{p}<.01$

Definitions: standard deviation (SD); ANOVA F-statistic (F); degrees of freedom (df); partial-eta squared effect size $\left(\eta^{2}\right)$

Table 1B. Bonferroni post-hoc tests for conversational indices and outcome variables for all pairwise conditions, after controlling for study/order and story topic interest ${ }^{a}$

\begin{tabular}{lllllllll}
\hline & Coor/Homo & Social & Interact & Informal & Friend & ArtCred & WebCred & Expert \\
\hline Twitter & 3.23 & 2.59 & 3.68 & 3.04 & 3.62 & 3.35 & 3.16 & 3.00 \\
Wikinews & 3.25 & 2.31 & 2.58 & 3.55 & 3.41 & 2.94 & 2.64 & 2.92 \\
& $(-.02)$ & $(.27)$ & $(1.11)$ & $(-.52)^{* *}$ & $(.22)^{*}$ & $(.41)^{* *}$ & $(.53)^{* *}$ & $(.18)$ \\
Twitter & 3.23 & 2.59 & 3.68 & 3.04 & 3.62 & 3.35 & 3.16 & 3.00 \\
Collaborative & 3.29 & 2.46 & 4.00 & 3.10 & 3.72 & 3.60 & 3.45 & 3.18 \\
& $(-.06)$ & $(.13)$ & $(-.29)^{* *}$ & $(-.36)^{*}$ & $(-.10)$ & $(-.25)$ & $(-.29)^{*}$ & $(-.18)$ \\
Wikinews & 3.25 & 2.31 & 2.58 & 3.55 & 3.41 & 2.94 & 2.64 & 2.82 \\
Collaborative & 3.29 & 2.46 & 4.00 & 3.40 & 3.72 & 3.60 & 3.45 & 3.18 \\
& $(-.04)$ & $(-.13)$ & $(-1.40)^{* *}$ & $(.16)$ & $(-.32)^{* *}$ & $(-.66) * *$ & $(-.82)^{* *}$ & $(-.36)^{*}$ \\
\hline
\end{tabular}

$* \mathrm{p}<.05 * * \mathrm{p}<.0$.

a All numbers rounded up to the nearest one-hundredth place

Beginning with H1, which predicted social presence, informality and friendliness scores would be highest in the Twitter condition, that was the case only with friendliness. And with friendliness, Twitter $(\mathrm{M}=3.62)$ only scored higher than Wikinews $(\mathrm{M}=3.41)$, at $\mathrm{p}=.04$, but not collaborative $(\mathrm{M}=3.72)$.

The next set of hypotheses about Wikinews found partial support. Scores for coorientation/homophily were expected to be highest here, H2a, but showed no difference. As for scores being lowest in this condition for social presence, interactivity and friendliness, $\mathbf{H 2 b}$, that was the case only for interactivity. There, the wiki story $(\mathrm{M}=2.58)$ scored lower than both the Twitter story $(\mathrm{M}=3.68)$ at $\mathrm{p}=.00$ and collaborative story $(\mathrm{M}=4.0)$ at $\mathrm{p}$ $=.00$. On the variable friendliness, meanwhile, the wiki story $(\mathrm{M}=3.41)$ was lower than only the collaborative story $(\mathrm{M}=3.72)$, at $\mathrm{p}=.00$.

Hypotheses related to the collaborative condition found relatively strong support. H3a predicted scores on interactivity would be highest in collaborative stories. That was the case only compared with Wikinews: the collaborative story's mean $(\mathrm{M}=4.00)$ easily exceeded that of wiki's $(2.58)$ at $\mathrm{p}=.00$ but was not significantly different from Twitter's $(\mathrm{M}=3.68)$.

H3b, meanwhile, predicted scores on the other conversation variables would never be statistically lowest in the collaborative condition. That was indeed the case, either because collaborative scores were statistically higher than other conditions, or relatively high but not significantly so. On informality, for instance, collaborative scores $(\mathrm{M}=3.40)$ were higher than Twittter's $(\mathrm{M}=3.04)$ at $\mathrm{p}=.05$ but not significantly different from Wikinews' $(M=3.55)$. On friendliness, collaborative scores $(M=3.72)$ were statistically higher than Wikinews' $(\mathrm{M}=3.41)$, at $\mathrm{p}=.00$, but not significantly different from Twitter's $(\mathrm{M}=3.62)$. On coorientation/homophily, collaborative scores $(M=3.29)$ were higher than scores for Wikinews $(M=3.25)$ and for Twitter $(M=3.23)$ but not significantly. Likewise, on social presence, scores were relatively high for collaborative stories $(\mathrm{M}=2.46)$ but not significantly different from Wikinews stories $(M=2.31)$ or from Twitter stories $(\mathrm{M}=2.59)$.

The final hypothesis, H4, predicted collaborative stories would score the highest on perceived article credibility, Web site (source) credibility and expertise. That was partially the case. Collaborative scores for Web site credibility $(\mathrm{M}=3.45)$ were significantly higher than scores for Twitter $(\mathrm{M}=3.16, \mathrm{p}=.03)$ and for Wikinews $(\mathrm{M}$ $=2.64, \mathrm{p}=.00)$. Meanwhile, collaborative scores for article credibility $(\mathrm{M}=3.60)$ were significantly higher than those for Wikinews stories $(\mathrm{M}=2.94)$, at $\mathrm{p}=.00$, but not significantly different from scores for Twitter $(\mathrm{M}=$ 3.35). On perceived expertise, collaborative scores $(\mathrm{M}=3.18)$ were significantly higher than Wikinews scores $(\mathrm{M}=2.82)$, at $\mathrm{p}=.03$, but not significantly different from Twitter's $(\mathrm{M}=3.00)$.

\subsection{The Regressions}

To better understand the mixed results for MANCOVAS, the author ran a series of hierarchical linear regressions as a form of secondary analysis to determine if any conversation variables predicted either type of credibility or expertise in any condition. To summarize those findings, coorientation/homophily proved operant in nearly every condition for most DVs, after controlling for study/order, topic interest and demographic variables (see Tables 2A-2C). For instance, the variable explained 63 percent of the variance (total R-squared) for expertise in 
collaborative stories. Also a powerful predictor in most models was interactivity, alone explaining 42 percent of the variance for expertise in the Twitter condition.

Further, in combination, coorientation/homophily and interactivity explained 34 percent of the variance of article credibility in that same condition. Informality and friendliness, meanwhile, sometimes worked against credibility and expertise in various conditions, as indicated by negative betas. Indeed, the lack of formality in combination with coorientation/homophily and interactivity accounted for 60 percent of the variance for expertise in the wiki condition.

Table 2A. Hierarchical Linear Regressions for twittered stories: Impact of conversation variables in standardized betas on dependent variables, after controlling for study/order, story topic interest and demographic variables

\begin{tabular}{lllll}
\hline Blocks of Independent Variables & Article Credibility & Website Credibility & Expertise \\
\hline Control (1) & Study/Order & .10 & .07 & .20 \\
\hline Control (2) & Topic interest & -.22 & -.07 & -.06 \\
\hline Demographics & Age & -.02 & -.24 & .02 \\
& Gender & .01 & -.09 & -.03 \\
& Ethnicity & .05 & -.34 & .18 \\
& Native USA & -.31 & .39 & .14 \\
\hline Conversation Variables & Coorient/Homophily & $.51^{* *}$ & $.49^{* *}$ & .17 \\
& Social Presence & .05 & -.03 & .03 \\
& Interactivity & $.28^{* *}$ & $.25^{*}$ & $.25^{*}$ \\
& Informality & -.01 & $-.34^{* *}$ & .00 \\
& Friendliness & -.19 & .06 & .11 \\
\hline Total R-squared & & .34 & .49 & .42 \\
\hline Adjusted R-squared & & .20 & .37 & .29 \\
\hline
\end{tabular}

$* \mathrm{p}<.05 * * \mathrm{p}<.01$.

Table 2B. Hierarchical Linear Regressions for wiki stories: Impact of conversation variables in standardized betas on dependent variables, after controlling for study/order, story topic interest and demographic variables

\begin{tabular}{lllll}
\hline Blocks of Independent Variables & Article Credibility & Website Credibility & Expertise \\
\hline Control (1) & Study/Order & -.13 & -.06 & .15 \\
\hline Control (2) & Topic interest & $-.28^{*}$ & $-.24^{*}$ & .00 \\
\hline Demographics & Age & .01 & -.02 & -.01 \\
& Gender & -.14 & -.08 & -.09 \\
& Ethnicity & .26 & .29 & -.08 \\
& Native USA & -.04 & -.07 & .22 \\
\hline Conversation Variables & Coorient/Homophily & $.37^{* *}$ & $.39^{* *}$ & $.36^{* *}$ \\
& Social Presence & .06 & .05 & .08 \\
& Interactivity & $.46^{* *}$ & $.45^{* *}$ & $.41^{* *}$ \\
& Informality & -.14 & -.17 & $-.39^{* *}$ \\
& Friendliness & .08 & .02 & -.02 \\
\hline Total R-squared & & .50 & .48 & .60 \\
\hline Adjusted R-squared & & .39 & .37 & .51 \\
\hline F** & & &
\end{tabular}
$* \mathrm{p}<.05 * * \mathrm{p}<.01$.

Table 2C. Hierarchical Linear Regressions for collaborative stories: Impact of conversation variables in standardized betas on dependent, after controlling for study/order, story topic interest and demographic variables

\begin{tabular}{lllll}
\hline Blocks of Independent Variables & Article Credibility & Website Credibility & Expertise \\
\hline Control (1) & Study/Order & -.01 & -.03 & -.10 \\
\hline Control (2) & Topic interest & -.01 & .14 & .01 \\
\hline Demographics & Age & .13 & -.06 & -.14 \\
& Gender & -.01 & -.07 & -.11 \\
& Ethnicity & .23 & .27 & .26 \\
& Native USA & -.36 & -.15 & -.02 \\
\hline Conversation Variables & Coorient/Homophily & .21 & .25 & $.38^{* *}$ \\
& Social Presence & .18 & .06 & .06 \\
& Interactivity & .07 & .10 & .07 \\
& Informality & -.22 & -.01 & -.22 \\
& Friendliness & -.18 & $-.30 *$ & .11 \\
\hline
\end{tabular}




\begin{tabular}{llll}
\hline Total R-squared & .35 & .29 & .63 \\
\hline Adjusted R-squared & .21 & .13 & .39 \\
$<<.05^{* * \mathrm{p}<.01 .}$ & & &
\end{tabular}

\section{Discussion}

This exploratory study sought to understand whether news audiences differentiate conversational features in certain stories, as proposed in a new measurement model, and even view some texts as more credible or expert. Results were mixed, with most hypotheses only partially supported. Findings suggest audiences do pick up on certain features of conversation in different texts, as evidenced by partial or complete support for $\mathbf{H 1}, \mathbf{H 2 b}$, $\mathbf{H 3 a} / \mathbf{b}$ and $\mathbf{H 4}$, though not always in a predictable manner. That unpredictability may be because of the newness of the measurement model and exploratory nature of this experiment. But it also may be because of the complexity of the phenomenon in the audience experience.

Some of the strongest findings related to the collaborative texts, which somewhat balance qualities of traditional and conversational journalism. There, readers responded moderately to each of the conversation features in the model, as predicted in $\mathbf{H 3 b}$, but also in some cases viewed such stories as more credible than other types, or $\mathbf{H 4}$. Those collaborative stories, unlike the wiki stories, clearly were written by professional mainstream journalists whom participants may be accustomed to reading. But the collaborative texts, unlike many traditional stories, carry a preponderance of quotations from everyday people rather than public officials, stress real-people anecdotes and essentially are told from the perspective of readers.

Also, more than the wiki and Twitter stories, collaborative stories clearly and explicitly told readers both in editor's notes and within texts how much the professional journalist went out of her way to connect with everyday people to tell a story. Showing, rather than telling, readers that a journalist connected with everyday people is important, as relatively high scores for the Twitter condition suggest. But telling, and even over-emphasizing, it to readers appears even more influential, as collaborative scores would indicate. News organizations would be wise to consider these results.

Among the more surprising findings, though, were scores for coorientation/homophily, or perceived similarity. Even when Wikinews exclaimed to readers it was written by everyday people just like them, and not standoffish professionals as some might describe, readers still did not perceive themselves as similar to the writers, showing no support for H2a. What is more, readers gave those wiki stories the lowest scores for credibility and expertise as revealed in MANCOVAs, perhaps the clearest evidence that readers trust journalism by professionals, despite research that suggests mainstream journalists are losing public trust (Pew, 2012).

Findings also suggest that social presence might work best with the help of video. In this study's written texts, readers did not perceive the humanness of the journalist, no matter how hard the words tried to convey it. In contrast, participants in Experiment 1 did respond when videos of journalists accompanied texts. The results echo findings in Newhagen and Nass' (1988) seminal study on perceived differences of TV and newspaper credibility. News consumers do indeed respond well to a human presence in the news, but seeing the journalist in video might matter most.

Less clear from this study is how other conversational features operate in different news stories. Though this study predicted readers would view the Twitter condition as most informal, particularly in light of the casual exchange shown between the journalist and citizens on Twitter, or H1, readers responded more to the essay-like prose of Wikinews. The language there was far from crisp and somewhat colloquial compared with professional news stories, and that apparently made a strong impression.

Also of interest are scores on friendliness. Again, this study intended the depiction of a quick, casual exchange on Twitter between a journalist and citizens to best show openness and friendliness, also H1. But readers responded more to the collaborative stories, which told them in several ways that the journalist had reached out to numerous citizens, in effect opened up to them, in her reporting. Telling readers the extent to which the journalist reached out, then, appeared crucial.

Regressions helped clarify how conversational features work toward credibility and expertise, but the analyses also complicate the situation somewhat. Most intriguing is coorientation/homophily's role as a key predictor in almost every story condition and yet the variable's weak showing in MANCOVAs. In other words, though coorientation/homophily predicted credibility and expertise in most cases, participants did not perceive significant differences on the variable among story types. This requires fleshing out in future experimental tests. 
The conversation variables informality and friendliness, meanwhile, proved somewhat problematic in the measurement model, most clearly with Wikinews. Readers perceived that story type as the most informal of all conditions, as MANCOVAs revealed, but also the least expert. Informality also worked against Web site credibility in the Twitter condition, meaning the more casual the journalist appeared to be, the less credible readers found the organization behind her, perhaps as though the organization failed to properly train her. Similarly, the journalist's perceived friendly openness in collaborative stories hurt Web site credibility in that condition.

From a practical standpoint, the findings in sum suggest journalists should tread carefully when inviting everyday citizens into news processes. Journalism-as-a-conversation appears to be a powerful, multidimensional phenomenon in the audience experience but far from monolithic and somewhat difficult to predict. Explicitly telling audiences how and why citizens informed coverage seems key, and possibly so does the use of video to help convey journalists' humanness. In addition, if audiences are looking to coorient with journalists around news by finding intellectual and demographics similarities, then newsrooms ought to consider posting short biographies and videos of each journalist on their websites. This gives audiences a deeper sense of who the journalists behind the news are. Finally, journalists should take care not to come across in stories as overly friendly or casual with citizens, at least if audience trust is a goal.

None of the findings is definitive, though, without more research. Most urgently needed are additional experiments that tease apart just how much informality and friendliness is acceptable, if any, in various types of conversational stories. The issue may simply be a matter of degree, or that these features do not belong in the measurement model. Also, while experiments allow for generalizing to theory based on variable relationships (Shapiro, 2002), even with student convenience samples (Lang, 1996), such studies cannot be generalized to human populations. That is a key goal of surveys. Future research, then, should test conversation initiatives in real newsrooms, perhaps with an eye on features explored in this study's model. Minnesota Public Radio/American Public Media's Public Insight Network initiative, where according to its site an electronic network of some 200,000 citizen sources offer their experiences and expertise to journalists, represents an advanced, longstanding conversational news effort worthy of such study.

\section{Acknowledgements}

The author thanks Dr. Esther Thorson of Missouri School of Journalism for help in building the conversation model and the editor and reviewers of this article for their thoughtful critiques.

\section{References}

Althen, G. (1992). The Americans have to say everything. Communication Quarterly, 40(4), 413-421. http://dx.doi.org/10.1080/01463379209369859

Anderson, R., Dardenne, R., \& Killenberg, G. (1996). The conversation of journalism: Communication, community, and news. Westport, CONN: Prager.

Briggs, M. (2010). Journalism next. Washington, D. C.: CQ Press.

Carey, J. W. (1992). The press and the public discourse. Kettering Review (winter), 9-22.

Chung, D. (2008). Interactive features of online newspapers: Identifying patterns and predicting use of engaged readers. Journal of Computer-Mediated Communication, 13, 658-679. http://dx.doi.org/10.1111/j.1083-6101.2008.00414.x

Domingo, D., Quandt, T., Heinonen, A., Paulussen, S., Singer, J., \& Vujnovic, M. (2008). Participatory journalism practices in the media and beyond: An international comparative study of initiatives in online newspapers. Journalism Practice, 2(3), 326-342. http://dx.doi.org/10.1111/j.1083-6101.2008.00415.x

Garko, M. G. (1992). Persuading subordinates who communicate in attractive and unattractive styles. Management Communication Quarterly, 5(3), 289-315. http://dx.doi.org/10.1177/0893318992005003002

Gaziano, C., \& McGrath, K. (1986). Measuring the concept of credibility. Journalism Quarterly, 63, 451-462. http://dx.doi.org/10.1177/107769908606300301

Gillmor, D. (2006). We the media: Grassroots journalism by the people, for the people. Sebastopol, CA: O'Reilly Media.

Gunawardena, C. N. (1995). Social presence theory and implications for interaction and collaborative learning in computer conferences. International Journal of Educational Telecommunications, 1(2/3), 147-166. 
Hamman, B. (2006). Two voices: Social presence, participation, and credibility in online news. Unpublished master's thesis, University of Missouri-Columbia, Columbia, MO.

Hermida, A. (2010). Twittering the news: The emergence of ambient journalism. Journalism Practice, 4(3), 297-308. http://dx.doi.org/10.1080/17512781003640703

Hermida, A., Lewis, S., \& Zamith, R. (2012). Sourcing the Arab Spring: A case study of Andy Carvin's sources during the Tunisian and Egyptian Revolutions. Paper presented at the annual International Symposium on Online Journalism conference, Austin, Texas.

Hovland, C. I., Janis, I. L., \& Kelley, H. H. (1953). Communication and persuasion. New Haven: Yale University Press.

Java, A., Song, X., Finin, T., \& Tseng, B. (2007). Why we Twitter: Understanding microblogging usage and communities. Paper submitted to proceedings of the Joint Ninth WEBKDD and First SNA-KDD Workshop 2007, Baltimore, August.

Kunelius, R. (2001). Conversation: A metaphor and a method for better journalism? Journalism Studies, 2(1), 31-54. http://dx.doi.org/10.1080/14616700120021793

Lang, A. (1996). The logic of using inferential statistics with experimental data from nonprobability samples: Inspired by Cooper, Dupagne, Potter, and Sparks. Journal of Broadcasting and Electronic Media, 40, 422-430.

Marchionni, D. (2013). Journalism-as-a-conversation: A concept explication. Communication Theory, 23(2), 131-147.

Marchionni, D. (2013). Journalism-as-a-conversation: An experimental test of socio-psychological/technological dimensions in journalist-citizen collaboration. In press Journalism: Theory, Practice and Criticism.

McCroskey, J. C., Richmond, V. P., \& Daly, J. A. (1975). The development of a measure of perceived homophily in interpersonal communication. Human Communication Research, 1, 323-332.

Meyer, H., Marchionni, D. \& Thorson, E. (2010). The journalist behind the news: Credibility of straight, collaborative, opinionated and blogged "news." American Behavioral Scientist, 54(2), 100-119. http://dx.doi.org/10.1177/0002764210376313

Newhagen, J., \& Nass, C. (1988). Differential criteria for evaluating credibility of newspapers and TV news. Journalism Quarterly, 65, 567-588. http://dx.doi.org/10.1177/107769908906600202

Norton, R., \& Pettigrew, L. (1977). Communicator style as an effect determinant in attraction. Communication Research, 4, 257-282. http://dx.doi.org/10.1177/009365027700400302

Perloff, R. (2003). The dynamics of persuasion: Communication and attitudes in the 21st Century. Mahwah, NJ: Lawrence Erlbaum.

Pew Research Center for the People and the Press. (2012). Further decline in credibility ratings for most news organizations. Retrieved

from http://www.people-press.org/2012/08/16/further-decline-in-credibility-ratings-for-most-news organizations/

Rafaeli, S. (1988). Interactivity: From new media to communication. In R. P. Hawkins, J. M. Wiemann \& S. Pingree (Eds.) Advancing communication science: Merging mass and interpersonal process (pp. 110-134). Newbury Park, CA: Sage.

Reeves, B., \& Nass, C. (1996). The media equation: How people treat computers, television, and new media like real people and places. Cambridge: Cambridge University Press.

Rosen, J. (2006, June 27). The people formerly known as the audience [Web log post]. Retrieved from http://archive.pressthink.org/2006/06/27/ppl_frmr.html

Rosenberry, J. (2005). Few papers use online techniques to improve public communication. Newspaper Research Journal, 26(4), 61-73.

Schultz, T. (1999). Interactive options in online journalism: A content analysis of 100 U.S. newspapers. Journal of Computer-Mediated Communication, 5(1), 0-0. http://dx.doi.org/10.1111/j.1083-6101.1999.tb00331.x

Shapiro, M. (2002). Generalizability in communication research. Human Communication Research, 28(4), 491-500. 
Singer, J., Hermida, A., Domingo, D., Heinonen, A., Paulussen, S., Quandt, T., Reich, Z., \& Vujnovic, M. (2011). Participatory journalism: Guarding open gates at online newspapers. Chichester, England: John Wiley \& Sons.

Swan, K. (2002). Building learning communities in online courses: The importance of interaction. Education, Communication \& Information, 2(1), 23-49. http://dx.doi.org/10.1080/1463631022000005016

Tabachnick, B. G., \& Fidell, L. S. (2007). Using multivariate statistics. Boston: Pearson, Allyn \& Bacon.

Tamborini, R., \& Skalski, P. (2005). Vividness, social presence and persuasion: Reconsidering the influence of modality on attitude formation. Paper presented at the International Communication Association 2005 Annual Meeting, New York, NY.

Thorson, E., \& Duffy, M. (2006). A needs-based theory of the revolution in news use and its implications for the newspaper business (Tech. Rep.) Columbia, MO: University of Missouri-Columbia, Reynolds Journalism Institute at the School of Journalism.

Wackman, D. B. (1973). Interpersonal communication and coorientation. American Behavioral Scientist, 16(4), 537-550. http://dx.doi.org/10.1177/000276427301600405

\section{Attachment 1}

The following dependent variables measured how conversational participants found different story types, as well as how trustworthy and expert. Topic interest served as a control variable.

\section{Conversation}

These six variables theoretically indexed conversation:

\section{Coorientation (continuous)}

The scale to measure coorientation was based on conceptual definitions in the literature, particularly Wackman's (1973): "I felt like this reporter is a person kind of like me," "I understand the story's issue in the same way the reporter does," "I see myself as quite different from this reporter," "I think this reporter has my interests at heart and "I would find it quite difficult to talk with this reporter on this issue."

\section{Social presence (continuous)}

This variable was measured using a scale developed by Tamborini and Skalski (2005) and adapted to the current study to apply to a reader-reporter relationship: "I felt like I got to know the reporter," "At times, I felt like the reporter was in the room with me" and "I thought of the reporter while reading the article."

\section{Homophily (continuous)}

This study relied on McCroskey, Richmond and Daly's (1975) scale to measure homophily but adapted it for a five-point instrument. The questions asked the subject to indicate his or her feelings about the story writer on the following eight issues: "This reporter doesn't think like me," "This reporter is from a social class similar to mine," "This reporter behaves like me," "This reporter is of an economic situation different from mine," "This reporter is similar to me," "This reporter's status is like mine," "This reporter is unlike me" and "This reporter's background is different from mine."

\section{Interactivity (continuous)}

A scale was developed for this study with items based on Rafaeli's (1988) conceptual definition of interactivity as an iterative process. "There wasn't much interaction between the reporter and ordinary-people sources in the story," "This reporter seems to have engaged ordinary people to get the story" and "This story resulted from interactions between the journalist and ordinary people."

\section{Friendliness (continuous)}

A scale was developed for this study based on items in the literature, particularly Garko's (1992): "This journalist seems friendly," "This journalist has an open attitude toward people," "This journalist seems like a people person" and "This journalist seems to have an unfavorable attitude toward people."

\section{Informality (continuous)}

This scale also was derived for this study based on conceptual definitions in the literature, particularly Althen's (1992): "The language of the story is informal," "The reporter is speaking casually" and "The language of the story sounds formal." 


\section{Outcome variables}

The following three variables tested how credible and expert readers perceived the media messages.

Article credibility (continuous)

This measure relied on four questions modified from Gaziano and McGrath's (1986) study: "I think the article is accurate," "I believe what I read in the article," "I can trust what I read here" and "I'm not sure the article told the whole truth."

Web site (source) credibility (continuous)

This measure for news Web site credibility relied in part on the article-credibility scale that Hamman (2006) used. The four questions: "I think the articles on this Web site are accurate," "I don't think I'd trust what I read on this Web site," "I can rely on this site" and "I probably would believe most articles I read on this site."

Expertise (continuous)

This variable consisted of a trio of items based on Perloff (2003): "This reporter sounds like an expert on this topic," "The reporter sounds like she knows what she's talking about" and "The reporter has done her homework on this story."

\section{Control variable}

\section{Topic interest (continuous)}

This study used topics that might be of interest to college students, but because interest can vary, answers to the following items served as a control: "The topic is interesting to me," "I found this topic boring" and "The topic is relevant to my life."

\section{(cc) $\mathrm{BY}$}

This work is licensed under a Creative Commons Attribution 3.0 License. 